\title{
Climate Change Detection over Different Land Surface Vegetation Classes
}

Hongyan Dang, Nathan P. Gillett, Andrew J. Weaver ${ }^{\dagger}$ and Francis W. Zwiers

School of Earth and Ocean Sciences, University of Victoria, Victoria, British Columbia, Canada,

Revised for International Journal of Climatology, June 2006

\footnotetext{
${ }^{*}$ Now at: Climatic Research Unit, School of Environmental Sciences, University of East Anglia, UK

${ }^{\dagger}$ corresponding author address: School of Earth and Ocean Sciences, University of Victoria, PO Box 3055 Victoria, BC V8W 3P6. E-mail: weaver@uvic.ca
} 


\section{Abstract}

A global land cover classification data set is used to partition the globe into seven regions to study surface temperature changes over different vegetation/surface classes. Statistically significant warming is found from the year 1900 over all regions (except for the ice sheets over Greenland and Antarctica). Outputs from three coupled climate models (CGCM2, HadCM2 and the Parallel Climate Model) are used to examine the detection and attribution of surface temperature trends over the various vegetation classes for the past half century. An anthropogenic warming trend is detected in six of the seven regions. Observed trends are consistent with those simulated in response to greenhouse gas and sulphate aerosol forcing except over tropical forest and water where the models appear to overestimate the warming. The similarity between the resultant scaling factors for each region from the different models underscores the reliability of our detection results. 


\section{Introduction}

The IPCC Third Assessment Report (TAR) (Folland et al., 2001) reports that globallyaveraged instrumental surface temperatures records show increases estimated to be $0.4-0.8^{\circ} \mathrm{C}$ since the late 19th century to the year 2000. This warming is very unusual compared with the past 1000 to 2000 years of variation shown by proxy temperature data (Mann and Jones, 2003; Briffa et al., 2004; Cook et al., 2004; Moberg et al., 2005) and does not show any sign of ceasing as we enter the 21st century. There are also substantial spatial and temporal variations in surface air temperatures. At hemispheric scales, surface air temperatures show general warming trends since the start of the Industrial Revolution in both the Northern and Southern Hemispheres. At other planetary-scale levels, such as over land and ocean, average surface air temperatures also show warming trends during the same period (Folland et al., 2001). In smaller regions, a surface cooling may exist. Giorgi (2002) examined monthly surface air temperatures from the CRU (Climate Research Unit of the University of East Anglia) dataset (New et al., 1999, 2000) and found that the observed temperatures showed significant warming trends throughout the 20th century over the majority of 22 land regions of sub-continental scale. The exceptions were central America, eastern Africa and east Asia in summer. Another surface cooling example is from Doran et al. (2002). Their research suggests a net continental cooling of Antarctica over the period 1966 - 2000 based on an analysis of Antarctic meteorological data.

Studies conducted with terrestrial/oceanic carbon cycle models or coupled GCM-carbon models suggest that the climate change and changes in $\mathrm{CO}_{2}$ levels may have had substantial effects on ecosystems (Prentice et al., 2001). For example, one model simulated that C4 grassland will partially replace the Amazon rain forest (Prentice et al., 2001). It is of interest to estimate the possible future changes in climate and hence determine the potential ecosystem evolution in response to this climate change.

Future climate change is usually assessed through the use of complicated AtmosphereOcean General Circulation Models that include a range of future scenarios for greenhouse gas concentrations and sulphate aerosol loadings (Cubasch et al., 2001). Although uncertainties 
exist and different models may produce different results under various scenarios (Weaver and Zwiers, 2000; Zwiers, 2002), there is still great similarity between the projections of a global warming for the near term. The climate of this period "results from the climate's adjustment to changes in the greenhouse-gas content of the atmosphere that have already occurred, due to the large thermal inertia of the oceans" and indicates that the influences of greenhouse gases and sulphate aerosols partially offset each other (Zwiers, 2002). In the long run, the uncertainty range of the warming trend is large. In 2100, relative to 1990, projected surface air temperature increases could range from 1.4 to $5.8^{\circ} \mathrm{C}$ (Cubasch et al., 2001).

The IPCC TAR concluded, based on global studies, that "most of the warming observed over the last 50 years is attributable to human activities" (Mitchell et al., 2001). As mentioned at the start of this section, if the substantial observed changes in ecosystems under observed historical climate change can be linked to human activities, further changes in ecosystems can be expected under continued anthropogenic global warming in the future. What's more, we may still expect anthropogenic impacts on future ecosystems regardless of whether these impacts have already been documented.

The observed temperature changes can result from temperature variation arising from climate variability caused by the natural interactions between the major components of the climate system. They can also be the consequence of climate changes driven by external mechanisms that influence one or more of the climate system components (Hasselmann, 1997). External forcings have both natural and anthropogenic sources. Natural forcings include fluctuations of the solar constant and aerosol emissions from volcanic activities. Anthropogenic forcing indicates human-activity-driven concentration changes in atmospheric components such as greenhouse gases and sulphate aerosols as well as changes in underlying surface conditions of the atmosphere due to land-use and deforestation.

In the IPCC TAR, climate change detection and attribution studies mainly concentrated on the global scale, with the issue of regional-scale detection still in its infancy (Mitchell et al., 2001). Global climate change detection and attribution studies discussed in the TAR, such as Tett et al. (1999), Stott et al. (2001) and Mitchell et al. (2001), found that the anthropogenic greenhouse gases and tropospheric sulphate aerosols have had a detectable effect on surface air 
temperatures in the latter half of the 20th century. Similar results can also be found in Hegerl et al. (1997), Hegerl et al. (2003) and Hegerl et al. (2004). The research of Barnett et al. (2001), Reichert et al. (2002), Levitus et al. (2001) and Barnett et al. (2005) suggests a consistency between the observed ocean heat-content changes of the past half century and those that are simulated by coupled climate models in response to anthropogenic forcing. Gillett et al. (2003) found that anthropogenic greenhouse gases and sulphate aerosols have had a detectable influence on sea-level pressure over the second half the 20th century.

Regional-scale detection remains difficult because signal to noise ratios diminish with scale (Stott and Tett, 1998). Recently, however, a number of studies concerning the potential impact of climate change on smaller scales have appeared. Through the analysis of indices of several continental patterns, Karoly et al. (2003) found that the observed 1950-1999 North American surface temperature trend is consistent with the modelled response associated with anthropogenic changes in greenhouse gases and sulphate aerosols. In addition, the combined influence of anthropogenic greenhouse gas and sulfate aerosol forcing on surface temperature changes was found to be detectable on the continental scale for the second half of 20th century (Zwiers and Zhang, 2003). Stott (2003) also found that an increasing surface temperature trend due to greenhouse gases could be detected in six continental regions. Zhang et al. (2005) found clear detectable anthropogenic forcing effects in nine spatial regions ranging from global scale to country-wide (such as southern Canada and China). Finally, Gillett et al. (2004a) demonstrated that anthropogenic greenhouse gases and sulphate aerosols have had a detectable influence on fire-season warming of the Canadian forest region, while Karoly and $W u$ (2005) detected anthropogenic warming trends over many parts of the globe at scales of $500 \mathrm{~km}$. The purpose of this paper is to quantitatively understand the anthropogenic influence on recent surface temperature changes at regional scales through a detection and attribution study. The regions used here are defined on the basis of biome features of the surface types of the region.

It is well known that different land surface types can affect climate in a variety of ways, perhaps the most important being their effects on surface albedo, evapotranspiration, and the terrestrial carbon cycle. The regional biomass distribution is known to respond to, as well as feed back upon, climate change. Paleo-proxy records and paleoclimate modelling studies 
have been particularly helpful in assessing such vegetation responses and feedbacks (McAvaney et al., 2001; Meissner et al., 2003). Over long periods, climate change can cause important changes in the geographic distribution and abundance of major land cover types and animal habitats (Melillo, 1999; Parmesan and Yohe, 2003; Thomas et al., 2004). Hughen et al. (2004), for example, found a rapid shift between arid grassland and wet forest in the Cariaco region during deglacial high-latitude North Atlantic climate oscillations. Meta-analysis conducted by Root et al. (2003) and Root et al. (2005) has also revealed a discernible trend in the population of both animals and plants as a consequence of climate warming over the past century. O'Reilly et al. (2003) provided further evidence that climate warming has the potential to modify aquatic biota and ecosystems through its influence on the stability of the water column and hence nutrient transport.

Temperature changes over different biotic regions play an important role in climate impacts and feedbacks within the climate system. For example, the atmospheric methane concentration has a close relationship to the atmospheric temperature record (Wuebbles and Hayhoe, 2001), and the emission of methane from melting tundra increases in association with surface warming of this region. Different biota also respond to surface temperature changes through different mechanisms. As such, the analysis of simulated and observed changes over these separate regions may enhance our understanding of biotic feedbacks operating within the climate system. Since temperature changes over specific biome regions have not been systematically studied, it is useful to evaluate how the surface temperature has changed over such regions. In addition, it is important to identify, if possible, the causes of these changes, and in particular to consider whether there are links with anthropogenic forcing of the climate system.

The outline of the rest of this paper is as follows: In Section 2, temperature conditions over specific biome regions will first be systematically examined and assessed for significant warming or cooling trends. To understand whether these observed temperature changes are a result of natural internal variability of the climate system, or due to external forcings, Section 3 is dedicated to an investigation of the influence of anthropogenic emitted greenhouse gases and sulphate aerosols on regional temperature changes. A detection and attribution study is conducted to examine if the anthropogenic emission of the combined greenhouse gases and 
sulphate aerosols or the greenhouse gases alone have had a detectable influence on the regional temperature changes of the second half of the 20th century. A discussion and conclusion are presented in Section 4. 


\section{Climate Change over Different Land Surface Vegetation Classes}

\subsection{Partitioning of surface types}

We use the National Aeronautics and Space Administration (NASA), International Satellite Land Surface Climatology Project (ISLSCP), and Global Data Sets for Land-Atmosphere Models (GDSLAM) vegetation class data set (DeFries and Townshend, 1994) to define the biotic regions. This dataset describes the geographic distribution of 15 major land cover types on a $1^{\circ} \times 1^{\circ}$ (latitude $\times$ longitude) grid, based on data collected in 1987 (upper panel of

Figure 1). In order to obtain scales sufficiently large to allow regional scale climate change detection, the original 15 surface types are re-grouped into seven surface types (Table 1): (1) water (including oceans, lakes, seas and sea ice), (2) tropical forest (including subtropical forest), (3) temperate forest,(4) bare ground (including desert, bare ground, and grassland), (5) tundra, (6) cultivated land, and (7) continental ice (bottom panel of Figure 1). As the purpose of this paper is to analyze regional temperature changes, when defining the subregions, a major consideration is the latitude and spatial continuity of the candidate smaller surface classes. Some other features are also considered, but generally it is not possible to consider all influencing factors. For example, when grouping shrubs, desert, bare ground, C3 wooded grassland and C3 grassland together, both spatial continuity and their similar albedos are considered, while the surface roughness and evapotranspiration have been ignored.

\subsection{Analysis of regional surface air temperature changes}

The surface air temperature trends over the seven broad classes defined in Section 2.1 were analyzed using variance-adjusted 1870 - 2004 monthly mean surface temperature anomalies (HadCRUT2v - Jones et al. (2001)) with a spatial resolution of $5^{\circ} \times 5^{\circ}$ (latitude $\times$ longitude). This monthly dataset provides temperature anomalies relative to $1961-1990$. Since the value of the temperature anomaly at each point represents the average temperature anomaly of the whole $5^{\circ} \times 5^{\circ}$ area represented by this point, all 25 of the $1^{\circ} \times 1^{\circ}$ vegetation grid boxes in this area were assigned the same temperature anomaly as the centre point. In this way there was a corresponding temperature anomaly record for each vegetation box. 
Area-weighted, annual-mean temperature anomalies were calculated for each of the seven biotic regions. The annual temperature anomaly for a specific grid box was treated as missing if even one month within the year was missing. An ordinary least squares fit regression analysis was used to estimate the linear trends of temperature over these regions from the start of the 20th century and from the mid-20th century. A student's t-test, with degrees of freedom adjusted to account for serial correlation, was used to test the null hypothesis that no trend is present (von Storch and Zwiers, 1999).

The estimated trends, given in Table 2, reflect a general warming from 1900 to 2004 over all regions, with warming trends being even greater over the period from 1950 to 2004. No significant warming trend was observed over the continental ice sheet region during either time period. The warming trends in the other six surface classes were found to be statistically significant at the 5\% significance level. The warming trends increased in the second half of the 20th century (Figure 2). The greatest warming happened over tundra and the temperate forest region and these trends are more apparent from 1950 onward. This is consistent with Giorgi et al. (2001) whose results suggest that nearly all land areas warm more rapidly than the global average, especially at high latitudes. The warming over water is smaller than over the land areas during this period, as expected from the high heat capacity of water relative to land.

There is a period of cooling from 1946 to 1975 in all regions except bare ground. These regional coolings are generally consistent with the global changes of the same period. The global cooling of this period can be reproduced in climate model simulations of the 20th century when natural forcing mechanisms are included in addition to the greenhouse gas and sulphate aerosol concentration changes. The inclusion of natural volcanic aerosol forcing is particularly important in this regard. 


\section{Detection and Attribution Analysis of Regional Climate Change Using Optimal Fingerprinting}

In this section, a detection and attribution analysis using optimal fingerprinting is carried out to examine the temperature response to increasing anthropogenic greenhouse gases and sulphate aerosols. The task of a detection and attribution study is to determine whether an observed climate change is internally generated by the climate system itself or forced by one of several external factors that might have affected the climate, such as greenhouse gas forcing. For this purpose, we assume internal climate variability and the responses to the various external forcings contribute linearly to observed climate change, as suggested by previous studies (Santer et al., 1995; Gillett et al., 2004b; Hasselmann, 1993, 1997, 1998; Hegerl et al., 1997; Allen and Tett, 1999; Allen and Stott, 2003).

In this analysis we use the optimal detection approach detailed in Allen and Stott (2003). This approach explicitly quantifies the relationship between the model simulated signal and the observed signal by assuming that the observations $\mathbf{y}$ can be expressed as a linear sum of the scaled simulated responses to external forcings $\mathbf{x}$, and residual variability $\mathbf{u}$ :

$$
\mathbf{y}=\mathbf{x} \beta+\mathbf{u}
$$

The simulated response $\mathbf{x}$ is obtained from an ensemble of transient climate simulations of the 20th century involving greenhouse gases, aerosols, and in some cases other external forcing changes (based on estimates of historical forcing changes over the 20th century). The best

guess of $\beta$ is calculated by minimizing the estimated total least squares residual from the true signals, while the significance (for example, $90 \%$ confidence limits) of $\beta$ is estimated based on the assumed distribution of the internal variability.

Conclusions about signal detection and signal attribution can be drawn based on the amplitude of the regression coefficient $\beta$. The externally forced signal pattern is said to be detected in the observed data if the estimate of $\beta$ is significantly greater than zero. Otherwise, the observed changes might be caused by other mechanisms such as natural internal climate vari- 
ability or forcings that are not included in the simulations. The analysis contributes to the attribution of a detected climate change signal to a particular forcing agent if the amplitude of $\beta$ is consistent with unity, that is, the observed signal is consistent with the model-simulated response to the specified external forcing, after accounting for all plausible forcing agents. "The scaling factor $\beta$ adjusts the signal amplitude so that the scaled signal best matches the observations" (Zwiers and Zhang, 2003). The forced simulation underestimates the amplitude of the observed signal if $\beta>\mathbf{1}$ while it overestimates the observed signal if $\beta<\mathbf{1}$ (Mitchell et al., 2001).

In this paper, a five-decade sequence of decadal mean regionally-averaged surface air temperatures (from 1946 to 1996) are used as the detection variable. Simulations from three climate models: PCM (Washington et al., 2000), HadCM2 (Johns et al., 1997), and CGCM2 (Flato and Boer, 2001), are used to estimate the internal variability. These climate models include control integrations of 1009 years with PCM, 1700 years with HadCM2, and 1000 years with CGCM2. The long control simulations of each model are used to estimate the covariance matrix of the internal climate variability. The entire lengths of the model control runs are also used to estimate the uncertainty range of the regression coefficient $\beta$.

Each of these three models also has several transient integrations with either greenhouse gas (G) forcing, or combined GS (greenhouse gases and and sulfate aerosols) forcing, which are available for estimating optimal fingerprints of temperature changes for the second half of the 20th century. In the case of the PCM, the GS runs used also contain stratospheric ozone forcing. The effect of stratospheric ozone depletion on surface temperature is small over most of the globe, although it has more profound effects on circulation and temperature in the free atmosphere (Gillett et al., 2003).

The fields of each model are masked in the same manner as the observations so that places without adequate observations are masked out of the model output. Then, as in Gillett et al. (2002), this study regresses five optimized observed decadal-mean surface temperature anomalies $(1946$ - 1956, 1956 - 1966, 1966 - 1976, 1976 - 1986, 1986 - 1996) onto the G or GS simulated anomaly patterns of surface temperatures over the same period. A mean temperature anomaly over each region is taken and a total least squares fit is used to estimate 
$\beta$ (Allen and Tett, 1999). The best guess of $\beta$ is calculated by minimizing the estimated least squares residual from the true signals, while the $90 \%$ confidence limits for $\beta$ are estimated from the simulated internal variability (Hegerl et al., 1997). We use a total least squares fit in this study for reasons of simplicity, however all single pattern results were found to be robust to our use of an ordinary least squares fit (Allen and Tett, 1999) to account for sampling variability in the simulated response patterns.

\subsection{Results}

The regression coefficients of the GS forcing experiments for the seven biotic regions are shown in Figure 3. The regression coefficients are significantly different from zero except for the tropical forest regions (in the HadCM2 case), the tundra regions (in the PCM case), and the ice region (in all three models). This implies that the observed temperature changes are not likely to be explained by natural internal climate variability alone. The significant positive values of $\beta$ over these regions indicate that an anthropogenic influence is detected in these cases. Both PCM and CGCM2 significantly overestimate the amplitude of the temperature anomaly response to the combined influence of increased greenhouse gases and sulphate aerosols in the water and tropical forest regions. An overestimation is also found in cultivated land regions by PCM. For the temperate forest and bare ground regions, the regression coefficients are consistent with unity in all three models.

In Figure 3 we can also see that the uncertainty in the scaling factors varies between models. This follows since the simulated internal climate variability and forced responses also vary between the models. The width of the uncertainty bars also tends to increase with a decrease in effective spatial scale of the land surface class (IDAG - International ad hoc Detection and Attribution Group, 2005). This is further amplified in regions where there is a lack of observational data. Nevertheless, estimates of the regression coefficients using different models are similar to each other in all regions. This consistency provides enhanced confidence in the detection of an anthropogenic influence on regional warming.

We can further search for the detection of a greenhouse gas signal in the observed temperature record over the different vegetation classes (Figure 4). With the exception of the tropical 
forest in HadCM2, tundra in PCM, and continental ice in all three models, a greenhouse gas influence on surface temperatures is found to be detectable. G alone forced climate models generate an overestimation of surface temperatures. In this study, in regions where the $\mathrm{G}$ alone signal has been detected, the upper limits of $\beta$ are generally less than one. The three models typically overestimate the warming signal and provide results that are remarkably consistent with each other as before. Still for these regions, the amplitudes of the estimates of $\beta$ from the combined GS forcing detection are generally closer to unity. This phenomenon can be explained by the compensation of the cooling effect of sulphate aerosols to the greenhouse gas warming effect on surface temperatures. External forcing that includes both $\mathrm{G}$ and $\mathrm{S}$ is closer to the real forcing in the atmosphere than G-forcing alone.

A two-way detection analysis using outputs from $\mathrm{G}$ simulations along with outputs from GS simulations relaxes the assumption that the relative magnitude of the $\mathrm{G}$ and $\mathrm{S}$ response in the GS simulation is correctly simulated by the climate model (Gillett et al., 2002). In this case, Equation 1 has the form $\mathbf{y}=\beta_{G} \mathbf{x}_{G}+\beta_{S} \mathbf{x}_{S}+\mathbf{u}$ and a total least squares regression is used here. According to Gillett et al. (2002), the estimated response to $\mathrm{S}$ forcing in each model is often computed as the difference between its GS simulation and G simulation, as a linear assumption is generally appropriate. Here both the integrations from the three individual models and a multi-model approach are used to separately estimate the amplitudes of the $\mathrm{G}$ and $\mathrm{S}$ regression coefficients, through a two-way regression approach. In the multi-model approach, GS and G simulations from all the three individual models are used to estimate the scaling factors. In addition, 800-year control segments from the three individual models (CGCM2, HadCM2 and PCM) are concatenated to derive an estimate of internal variability. In this way, both the signal and internal variability estimates account for the "structural" (i.e., model) uncertainty, at least to the extent that such uncertainty is represented by the difference between the three models.

G or S are listed in Table 3 if either pattern has been detected. The signal from greenhouse gases $\mathrm{G}$ has been separately detected in at least two individual models over every vegetation type except continental ice. G has also been detected over all regions but the continental ice by the multi-model approach. For G, the multi-model results provide a consensus between the 
individual model results. The S signal is separately detectable by PCM for all land regions except continental ice. The detection of S over water may have failed because the influence of $\mathrm{S}$ is mainly over land.

\section{Conclusions}

The evolution of local biota as well as the influences of local climate are closely related to local surface temperature changes. Since surface temperatures in regions smaller than continental scale display both warming and cooling trends in the past century, and this divergence has been found over regularly divided regions of the globe (Giorgi, 2002), the surface temperature trends over biotic regions are also expected to vary. The subsequent influences of these climatic changes on bio-systems may be very different from region to region. It is therefore necessary to examine how the instrumental surface temperature changes over major biome regions, as this examination has not been systematically conducted. It is also necessary to determine if there have been detectable signals of anthropogenic activities in these regions showing temperature changes as this is a necessary, but not sufficient, condition for concluding that the substantial changes in ecosystems over the corresponding period may be due to anthropogenic influences. This study is also valuable for studies on climatic effects on future ecosystem evolution such as shifts of plant distribution and wild animal habitat.

The detection of warming or cooling trends and the extent to which the trends are controlled by the anthropogenic emission of greenhouse gases and sulphate aerosols was examined here. The analysis of instrumental records of surface temperatures revealed pronounced warming trends over the major biotic regions on Earth, starting from the beginning of the 20th century. Superimposed upon this overall global warming trend were some periods of regional cooling.

Using three different climate models we found a detectable combined anthropogenic greenhouse gas and sulphate aerosol signal over water, tropical forest, temperate forest, bare ground, tundra and cultivated land regions. The warming effect of greenhouse gases alone on surface temperatures is also detectable over different regions by all climate models. Over every vegetation type except continental ice, at least two climate models have separately detected the 
influence of greenhouse gases. The $\mathrm{G}$ signals in six regions (except continental ice) have also been detected through a multi-model approach. S signal is separately detectable by PCM for all land regions except tundra and continental ice. The observed temperature changes in all the seven regions cannot be explained by natural forcing alone.

Observed regional climate change signals are consistent with combined $\mathrm{G}$ and $\mathrm{S}$ forcing over temperate forest, bare ground, and tundra both in three separate climate models and in the multi-model analysis. The same consistency has been found over cultivated land regions by both HadCM2 and CGCM2, while over global water, a consistency between climate change signal and GS forcing can only be found in HadCM2. We found that over temperate forest regions, the observed warming trend during the latter half century is also consistent with a greenhouse gas forcing mechanism alone in all three models through both the one-signal detection and two-signal detection. Although regional scale climate features simulated by climate models are not as reliable as those at a global scale (Hasselmann, 1993), the rather remarkable inter-model consistency of our detection results increases our overall confidence in the detectability of the anthropogenic signals at surface-type-based regional scales.

\section{Acknowledgements}

This research was supported by the CFCAS/NSERC Canadian CLIVAR research network. We are grateful to the Hadley Centre for Climate Prediction and Research and the Program for Climate Model Diagnosis and Intercomparison for allowing us to use their model output. 


\section{References}

Allen, M. R., and P. A. Stott (2003), Estimating signal amplitudes in optimal fingerprinting, part 1: Theory, Clim. Dyn., 21, 477-491.

Allen, M. R., and S. F. B. Tett (1999), Checking for model consistency in optimal fingerprinting, Climate Dynamics, 15, 419-434.

Barnett, T. P., D. W. Pierce, and R. Schnur (2001), Detection of anthropogenic climate change in the world's oceans, Science, 292, 270-274.

Barnett, T. P., D. W. Pierce, K. M. AchutaRao, P. J. Gleckler, B. D. Santer, J. M. Gregory, and W. M. Washington (2005), Penetration of human-induced warming into the world's oceans, Science, 309, 284-287.

Briffa, K. R., T. J. Osborn, and F. H. Schweingruber (2004), Large-scale temperature inferences from tree rings: a review, Global and Planetary Change, 40, 11-26.

Cook, E. R., J. Esper, and R. D. D'Arrigo (2004), Extra-tropical northern hemisphere land temperature variability over the past 1000 years, Quaternary Science Reviews, 23, 20632074 .

Cubasch, U., G. A. Meehl, G. J. Boer, R. J. Stouffer, M. Dix, A. Noda, C. A. Senior, S. Raper, and K. S. Yap (2001), Projections of future climate change, in Climate Change 2001. The Scientific Basis Contribution of Working Group 1 to the Third Assessment Report of the Intergovernmental Panel on Climate Change, edited by J. Houghton, Y. Ding, D. Griggs, M. Noguer, P. van der Linden, X. Dai, K. Maskell, and C. Johnson, pp. 527-582, Cambridge University Press.

DeFries, R. S., and J. R. G. Townshend (1994), Ndvi-derived land cover classification at global scales, International Journal of Remote Sensing, 15, 3567-3586, special Issue on Global Data Sets.

Doran, P., et al. (2002), Antarctic climate cooling and terrestrial ecosystem response, Nature, $415,517-520$. 
Flato, G. M., and G. J. Boer (2001), Warming asymmetry in climate change simulations, Geophys. Res. Lett., 28, 195-198.

Folland, C. K., et al. (2001), Observed climate variability and change, in Climate Change 2001. The Scientific Basis Contribution of Working Group 1 to the Third Assessment Report of the Intergovernmental Panel on Climate Change, edited by J. Houghton, Y. Ding, D. Griggs, M. Noguer, P. van der Linden, X. Dai, K. Maskell, and C. Johnson, pp. 99-181, Cambridge University Press.

Gillett, N. P., F. W. Zwiers, A. J. Weaver, G. C. Hegerl, M. R. Allen, and P. A. Stott (2002), Detecting anthropogenic influence with a multi-model ensemble, Geophys. Res. Lett., 29(20), 1970, doi:10.1029/2002GL015836.

Gillett, N. P., F. W. Zwiers, A. J. Weaver, and P. A. Stott (2003), Detection of human influence on sea-level pressure, Nature, 422, 292-294.

Gillett, N. P., A. J. Weaver, and M. D. Flannigan (2004a), Detecting the effect of climate change on canadian forest fires, Geophys. Res. Lett., 31(20), L18211, doi:10.1029/2004GL020876.

Gillett, N. P., M. F. Wehner, S. F. B. Tett, and A. J. Weaver (2004b), Testing the linearity of the response to combined greenhouse gas and sulfate aerosol forcing, Geophys. Res. Lett., 31, L14201, doi:10.1029/2004GL020111.

Giorgi, F. (2002), Variability and trends of sub-continental scale surface climate in the twentieth century. I. observations, Clim. Dyn., 18, 675-691.

Giorgi, F., B. Hewitson, J. Christensen, M. Hulme, H. V. Storch, P. Whetton, R. Jones, L. Mearns, and C. Fu (2001), Regional climate information - evaluation and projections, in Climate Change 2001. The Scientific Basis Contribution of Working Group 1 to the Third Assessment Report of the Intergovernmental Panel on Climate Change, edited by J. H. et. al., pp. 585-638, Cambridge University Press.

Hasselmann, K. (1993), Optimal fingerprints for the detection of time-dependent climatechange, J. Clim., 6, 1957-1971. 
Hasselmann, K. (1997), Multi-pattern fingerprint method for detection and attribution of climate change, Clim. Dyn., 13, 601-611.

Hasselmann, K. (1998), Conventional and bayesian approach to climate-change detection and attribution, Q. J. R. Meteorol. Soc., 124, 2541-2565.

Hegerl, G. C., K. Hasselmann, U. Cubasch, J. F. B. Mitchell, E. Roeckner, R. Voss, and J. Waszkewitz (1997), Multi-fingerprint detection and attribution analysis of greenhouse gas, greenhouse gas-plus-aerosol and solar forced climate change, Clim. Dyn., 13, 613-634.

Hegerl, G. C., T. J. Crowley, S. K. Baurm, K. Y. Kim, and W. T. Hyde (2003), Detection of volcanic, solar and greenhouse gas signals in paleo-reconstructions of northern hemispheric temperature, Geophys. Res. Lett., 30(5), 1242, doi:10.1029/2002GL016635.

Hegerl, G. C., F. W. Zwiers, P. A. Stott, and V. V. Kharin (2004), Detectability of anthropogenic changes in temperature and precipitation extremes, J. Clim., 17, 3683-3700.

Hughen, K. A., T. L. Eglinton, L. Xu, and M. Makou (2004), Abrupt tropical vegetation response to rapid climate changes, Science, 304, 1955-1959.

IDAG - International ad hoc Detection and Attribution Group (2005), Detecting and attributing external influences on the climate system: A review of recent advances, J. Clim., 18, $1291-1314$.

Johns, T., R. Carnell, J. Crossley, J. Gregory, J. Mitchell, C. Senior, S. Tett, and R. Wood (1997), The second hadley centre coupled ocean-atmosphere gcm: model description, spin-up and validation, Clim. Dyn., 13, 103-134.

Jones, P. D., T. J. Osborn, K. R. Briffa, C. K. Folland, E. B. Horton, L. V. Alexander, D. E. Parker, and N. A. Rayner (2001), Adjusting for sampling density in grid box land and ocean surface temperature time series, J. Geophys. Res., 106, 3371-3380.

Karoly, D., and Q. Wu (2005), Detection of regional temperature changes in surface temperature, J. Clim., in press. 
Karoly, D. J., K. Braganza, P. A. Stott, J. M. Arblaster, G. A. Meehl, A. J. Broccoli, and K. W. Dixon (2003), Detection of a human influence on north american climate, Science, 302, 1200-1203.

Levitus, S., J. I. Antonov, J. Wang, T. L. Delworth, K. W. Dixon, and A. J. Broccoli (2001), Anthropogenic warming of earth's climate system, Science, 292, 267-270.

Mann, M. E., and P. D. Jones (2003), Global surface temperatures over the past two millennia, Geophys. Res. Lett., 30(1820).

McAvaney, B., et al. (2001), Model evaluation, in Climate Change 2001. The Scientific Basis Contribution of Working Group 1 to the Third Assessment Report of the Intergovernmental Panel on Climate Change, edited by J. Houghton, Y. Ding, D. Griggs, M. Noguer, P. van der Linden, X. Dai, K. Maskell, and C. Johnson, pp. 471-523, Cambridge University Press.

Meissner, K., A. Weaver, H. Matthews, and P. Cox (2003), The role of land-surface dynamics in glacial inception: A study with the uvic earth system model, Clim. Dyn., 21, 515-537.

Melillo, J. M. (1999), Warm, warm on the range, Science, 283, 183-184.

Mitchell, J. F. B., D. J. Karoly, G. C. Hegerl, F. W. Zwiers, M. R. Allen, and J. Marengo (2001), Detection of climate change and attribution of causes, in Climate Change 2001: The Scientific Basis, Contribution of Working Group 1 to the Third Assessment Report of the Intergovernmental Panel on Climate Change, edited by J. Houghton, Y. Ding, D. Griggs, M. Noguer, P. van der Linden, X. Dai, K. Maskell, and C. Johnson, pp. 695-738, Cambridge University Press.

Moberg, A., D. M. Sonechkin, K. Holmgren, N. M. Datsenko, and W. Karlen (2005), Highly variable northern hemisphere temperatures reconstructed from low- and high-resolution proxy data, Nature, 433, 613-618.

New, M., M. Hulme, and P. D. Jones (1999), Representing twentieth-century space-time climate variability. part i: Development of a 1961-90 mean monthly terrestrial climatology, Journal of Climate, 12, 829-856. 
New, M., M. Hulme, and P. D. Jones (2000), Representing twentieth-century space-time climate variability. part ii: Development of 1901-96 monthly grids of terrestrial surface climate, Journal of Climate, 13, 2217-2238.

O'Reilly, C. M., S. R. Alin, P. Plisnier, A. S. Cohen, and B. A. McKee (2003), Climate change decreases aquatic ecosystem productivity of Lake Tanganyika, Nature, 424, 766-768.

Parmesan, C., and G. Yohe (2003), A globally coherent fingerprint of climate change impacts across natural systems, Nature, 421, 37-42.

Prentice, I. C., et al. (2001), The carbon cycle and atmospheric carbon dioxide, in Climate Change 2001: The Scientific Basis, Contribution of Working Group 1 to the Third Assessment Report of the Intergovernmental Panel on Climate Change, edited by J. Houghton, Y. Ding, D. Griggs, M. Noguer, P. van der Linden, X. Dai, K. Maskell, and C. Johnson, pp. 185-237, Cambridge University Press.

Reichert, B. K., R. Schnur, and L. Bengtsson (2002), Global ocean warming tied to anthropogenic forcing, Geophys. Res. Lett., 29(11), 1525, doi:10.1029/2001GL013954.

Root, T. L., J. T. Price, K. R. Hall, S. H. Schneider, C. Rosenzweig, and J. A. Pounds (2003), Fingerprints of global warming on wild animals and plants, Nature, 421, 57-60.

Root, T. L., D. P. MacMynowski, M. D. Mastrandrea, and S. H. Schneider (2005), Humanmodified temperatures induce species changes: Joint attribution, Proc. Nat. Acad. Sci., 102, $7465-7469$.

Santer, B. D., K. E. Taylor, T. M. L. Wigley, J. E. Penner, P. D. Jones, and U. Cubasch (1995), Towards the detection and attribution of an anthropogenic effect on climate, Clim. Dyn., 12, 77-100.

Stott, P. A. (2003), Attribution of regional-scale temperature changes to anthropogenic and natural causes, Geophys. Res. Lett., 30(14), 1728, doi:10.1029/2003GL017324.

Stott, P. A., and S. F. B. Tett (1998), Scale-dependent detection of climate change, J. Clim., $11,3282-3294$. 
Stott, P. A., S. F. B. Tett, G. S. Jones, M. R. Allen, W. J. Ingram, and J. F. B. Mitchell (2001), Attribution of twentieth century temperature change to natural and anthropogenic causes, Clim. Dyn., 17, 1-21.

Tett, S. F. B., P. A. Stott, M. R. Allen, W. J. Ingram, and J. F. B. Mitchell (1999), Causes of twentieth-century temperature change near the earth's surface, Nature, 10, 569-572.

Thomas, C. D., et al. (2004), Extinction risk from climate change, Nature, 427, 145-148.

von Storch, H., and F. W. Zwiers (1999), Statistical Analysis in Climate Research, Cambridge University Press.

Washington, W. M., et al. (2000), Parallel climate model PCM control and transient simulations, Clim. Dyn., 16(10-11), 755-774.

Weaver, A. J., and F. W. Zwiers (2000), Uncertainty in climate change, Nature, 40\%, 571-572.

Wuebbles, D. J., and K. Hayhoe (2001), Atmospheric methane and global change, Earth-Sci. Rev., 57, 177-210.

Zhang, X., F. W. Zwiers, and P. Stott (2005), Multi-model multi-signal climate change detection at regional scale, J. Clim, submitted.

Zwiers, F. W. (2002), The 20-year forecast, Nature, 416, 690-691.

Zwiers, F. W., and X. Zhang (2003), Toward regional-scale climate change detection, J. Clim., $16(5), 793-797$. 
Table 1: Partitioning of 16 land surface classes, as identified by NASA-ISLSCP-GDSLAMVegetation class dataset, into 7 re-grouped classes

\begin{tabular}{|c|l||l|c|}
\hline $\begin{array}{c}\text { Original surface } \\
\text { class number }\end{array}$ & $\begin{array}{l}\text { Original surface } \\
\text { class type }\end{array}$ & $\begin{array}{l}\text { Re-grouped surface } \\
\text { class type }\end{array}$ & $\begin{array}{c}\text { Re-grouped } \\
\text { number }\end{array}$ \\
\hline \hline 0 & Water & Water & 1 \\
\hline 1 & $\begin{array}{l}\text { Broadleaf forest } \\
\text { Broadleaf deciduous } \\
2\end{array}$ & Tropical forest & 2 \\
7 & Woost and woodland & & \\
\hline 3 & $\begin{array}{l}\text { Mixed coniferous } \\
\text { \&broadleaf deciduous } \\
\text { Coniferous forest } \\
\text { \&woodland }\end{array}$ & Temperate forest & 3 \\
4 & High latitude deciduous & & \\
\hline 5 & $\begin{array}{l}\text { Shrubs and bare ground } \\
\text { Desert and bare ground }\end{array}$ & Bare ground & \\
\hline 9 & C3 wooded grassland & & 4 \\
11 & C3 grassland & & \\
\hline 14 & Tundra & Tundra & \\
\hline 10 & Cultivated land & Cultivated land & 6 \\
\hline 12 & Ice & Continental ice & 7 \\
\hline 13 & C4 grassland & - & \\
\hline 8 & & & \\
\hline
\end{tabular}

Table 2: Estimated trends of regional surface temperature over two 20th century time periods in ${ }^{\circ} \mathrm{C} / 100 y r$; their $95 \%$ confidence intervals and estimated significance.

\begin{tabular}{|c|l||c|c||c|c|}
\hline $\begin{array}{c}\text { Surface class } \\
\text { number }\end{array}$ & $\begin{array}{l}\text { Surface class } \\
\text { type }\end{array}$ & $\begin{array}{c}1900-2004 \\
\left({ }^{\circ} \mathrm{C} / 100 \mathrm{yr}\right)\end{array}$ & Significance & $\begin{array}{c}1950-2004 \\
\left({ }^{\circ} \mathrm{C} / 100 \mathrm{yr}\right)\end{array}$ & Significance \\
\hline 1 & Water & $0.67 \pm 0.16$ & $<0.05$ & $0.77 \pm 0.38$ & $<0.05$ \\
\hline 2 & Tropical forest & $0.61 \pm 0.19$ & $<0.05$ & $1.12 \pm 0.43$ & $<0.05$ \\
\hline 3 & Temperate forest & $1.07 \pm 0.29$ & $<0.05$ & $2.26 \pm 0.64$ & $<0.05$ \\
\hline 4 & Bare ground & $0.87 \pm 0.26$ & $<0.05$ & $1.86 \pm 0.50$ & $<0.05$ \\
\hline 5 & Tundra & $0.95 \pm 0.41$ & $<0.05$ & $1.98 \pm 0.84$ & $<0.05$ \\
\hline 6 & Cultivated land & $0.72 \pm 0.21$ & $<0.05$ & $1.37 \pm 0.57$ & $<0.05$ \\
\hline 7 & Continental ice & $0.15 \pm 0.97$ & 0.75 & $0.33 \pm 0.77$ & 0.39 \\
\hline
\end{tabular}


Table 3: Separately detected G and S signals in surface class based warming by three climate models and the multiple model

\begin{tabular}{|c|l|c|c|c|c|}
\hline $\begin{array}{c}\text { Surface class } \\
\text { number }\end{array}$ & $\begin{array}{l}\text { Surface class } \\
\text { type }\end{array}$ & HadCM2 & CGCM2 & PCM & $\begin{array}{c}\text { Multi- } \\
\text { model }\end{array}$ \\
\hline 1 & Water & G & G & G & G \\
\hline 2 & Tropical forest & - & G,S & G,S & - \\
\hline 3 & Temperate forest & G,S & G & G,S & G,S \\
\hline 4 & Bare ground & G & G & G,S & G \\
\hline 5 & Tundra & G & G & - & G \\
\hline 6 & Cultivated land & G & - & G,S & G \\
\hline 7 & Continental ice & - & - & - & - \\
\hline
\end{tabular}
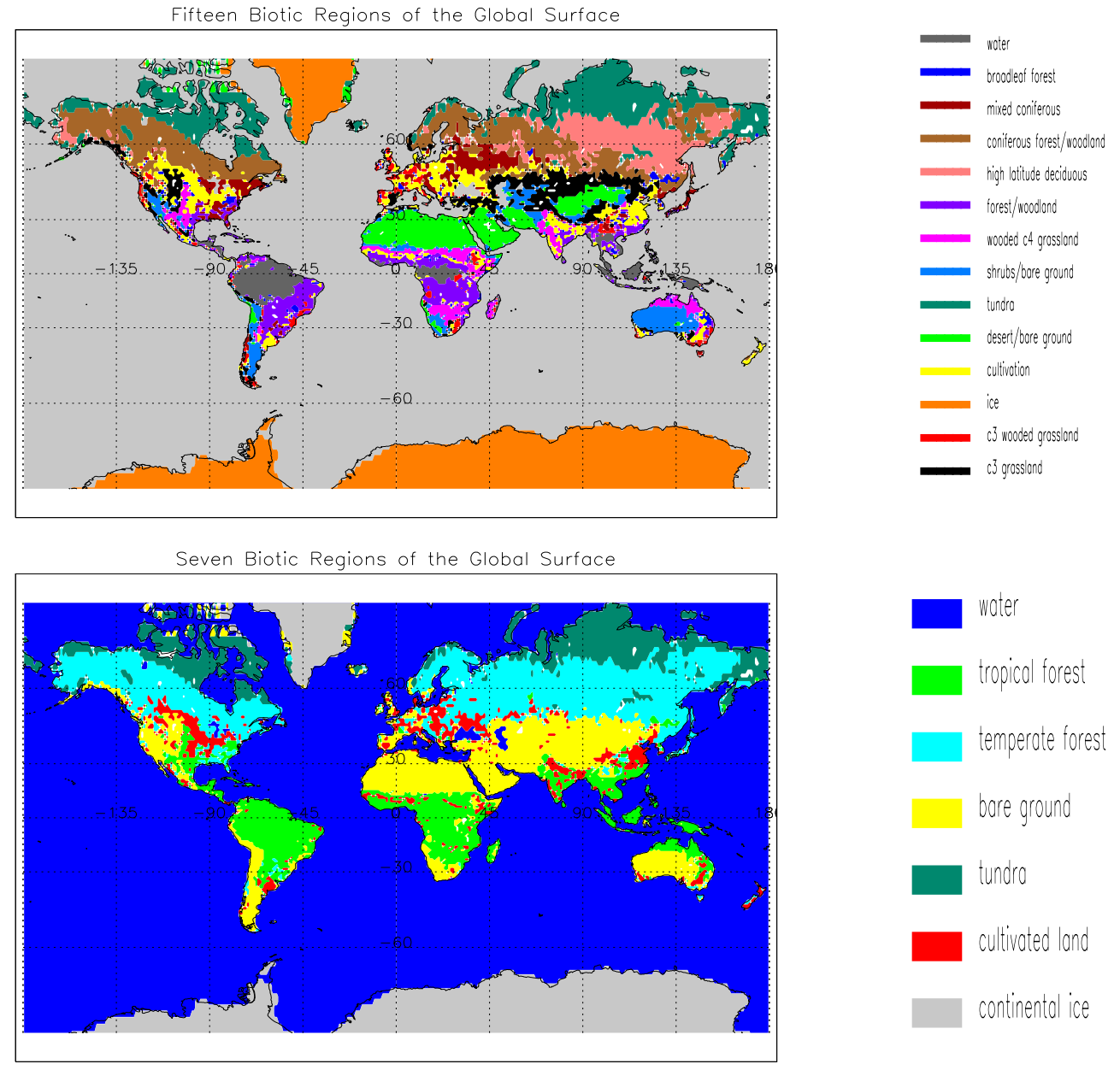

Figure 1: Upper: Distribution of original 15 surface types in the NASA-ISLSCP-GDSLAMVegetation class dataset. Bottom: Re-grouped seven subregions based on different vegetation/surface types. 

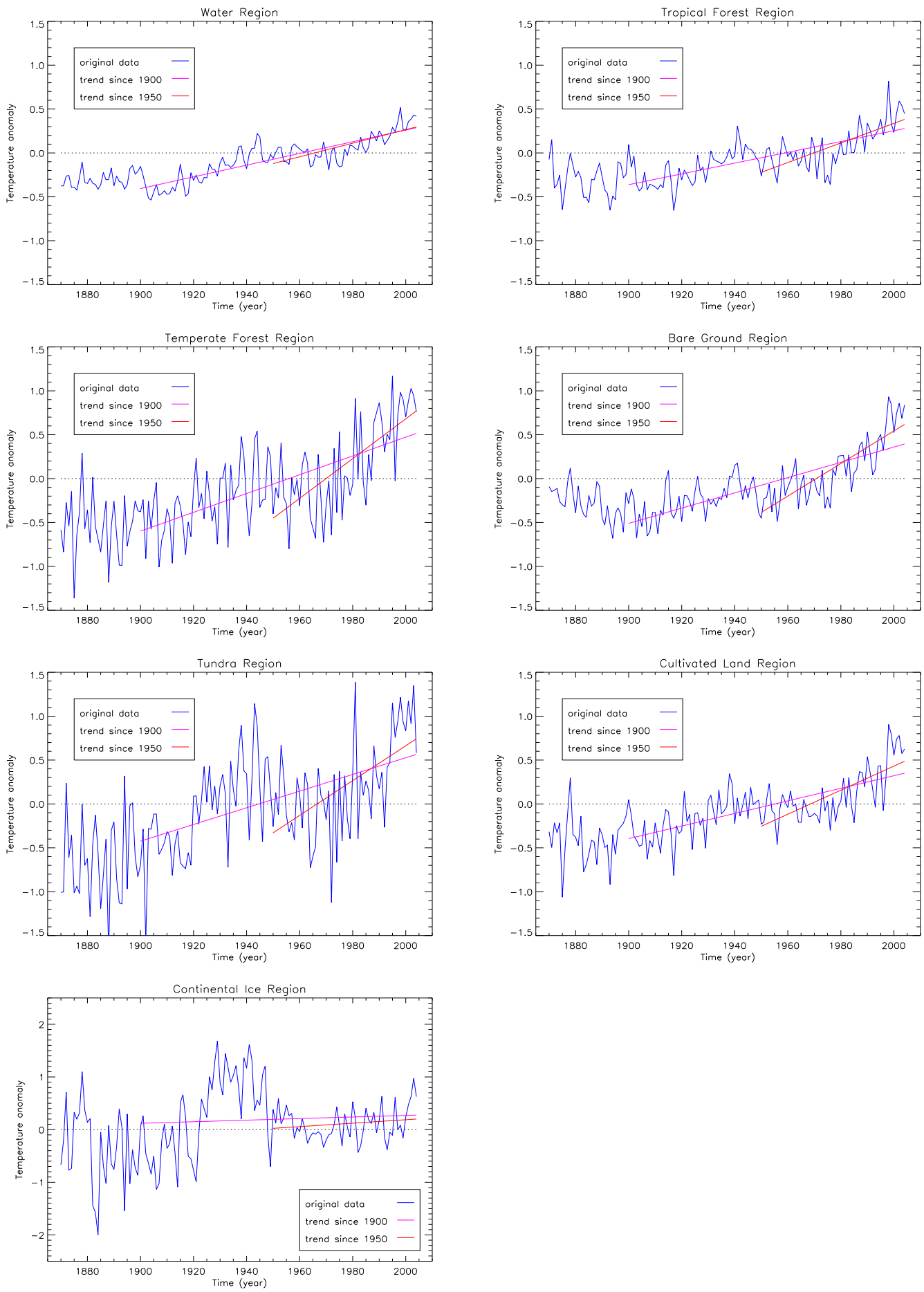

Figure 2: Surface warming trends in 6 of 7 biotic regions, as shown by temperature anomaly data and linear trends lines for two 20 th century time periods. 


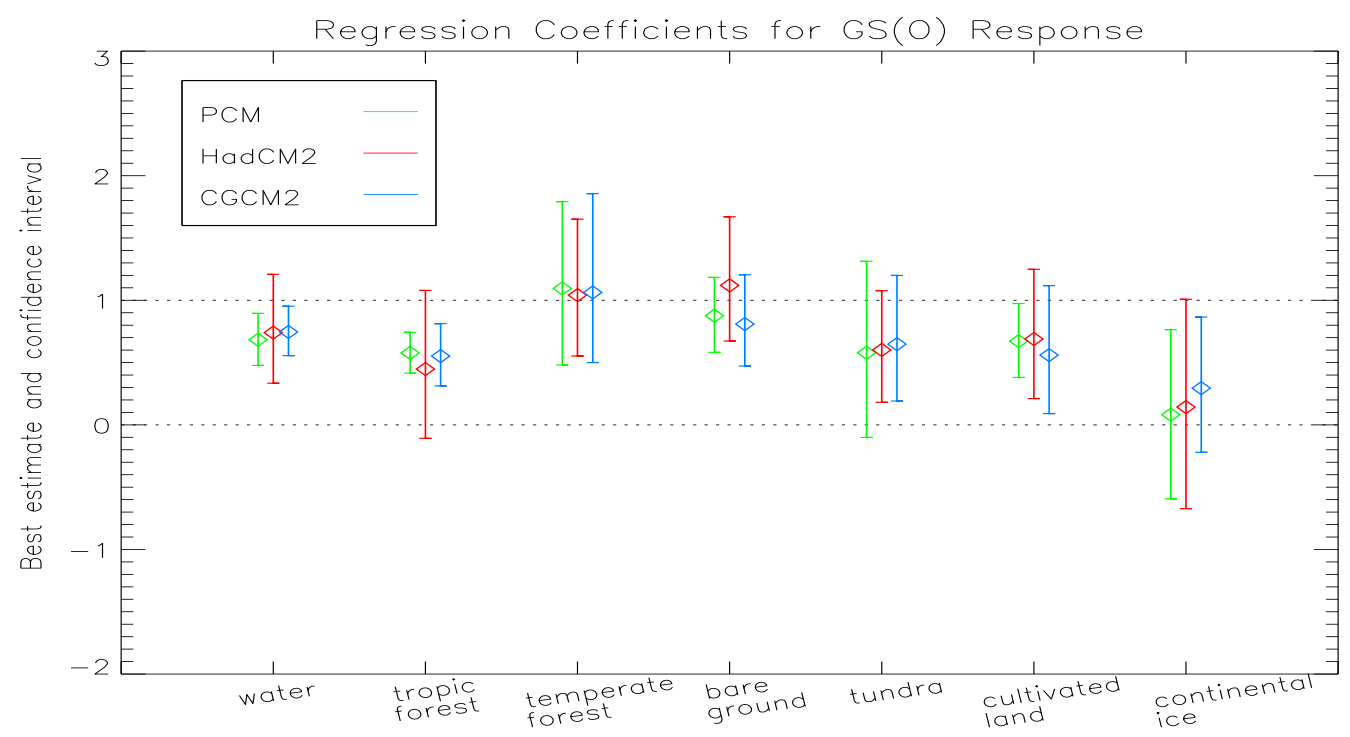

Figure 3: Best estimate of the regression coefficients $\beta$ and their 5-95\% uncertainty ranges, of observed surface temperature changes against simulated changes in three climate models forced by external forcings. External forcings are combined GS in HadCM2 and CGCM2, and combined GSO in PCM.

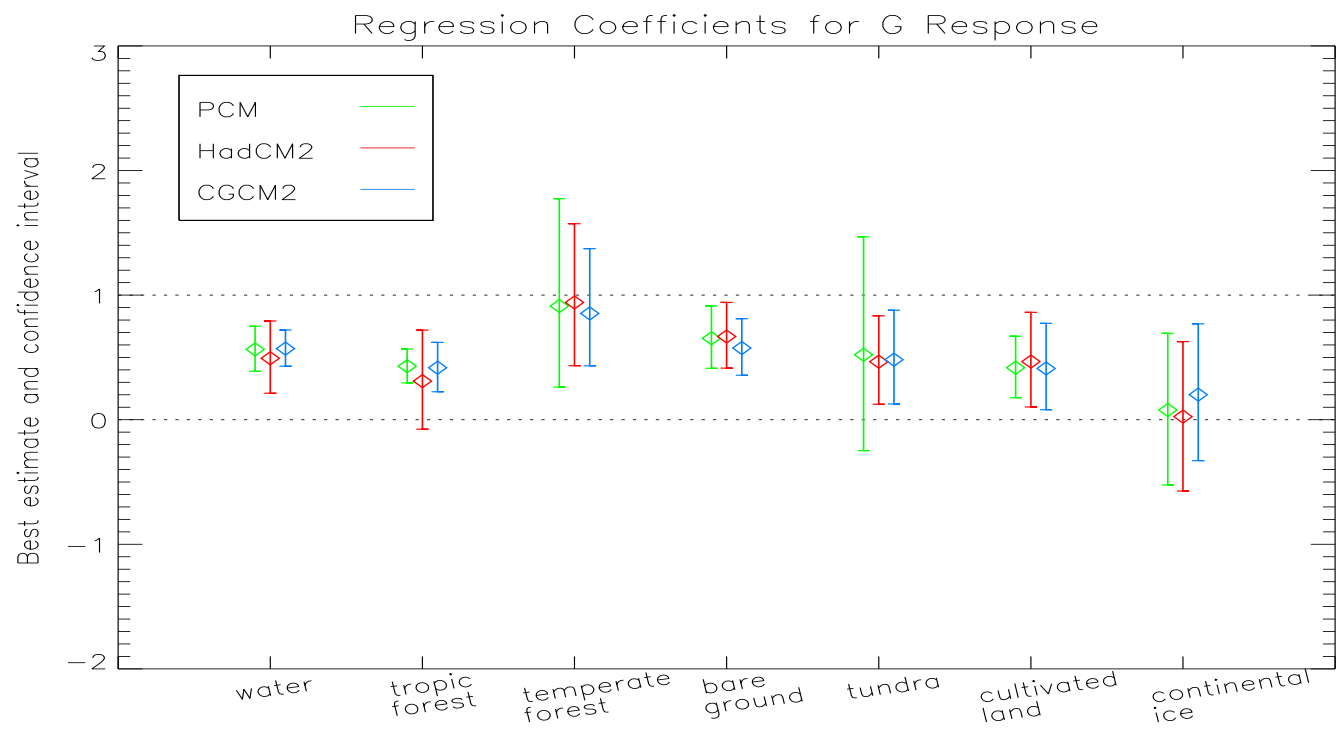

Figure 4: Best estimate of the regression coefficients $\beta$ and their 5-95\% uncertainty ranges, of observed surface temperature changes against simulated changes in three climate models forced by external forcings. External forcings are greenhouse gas alone. 